\title{
Migratory behaviour of the mangrove gastropod Cerithidea decollata under unfamiliar conditions
}

\author{
Anna Marta Lazzeri ${ }^{a}$, Nadia Bazihizina ${ }^{b}$, Pili K. Kingunge ${ }^{c}$, Alessia Lotti ${ }^{d}$, Veronica Pazzi ${ }^{d}$, \\ Pier Lorenzo Tasselli ${ }^{\text {e, Marco Vannini }}{ }^{\text {a, } * \text {, Sara Fratini }}{ }^{\text {a }}$ \\ a Department of Biology, University of Florence, via Madonna del Piano 6, I-50019 Sesto Fiorentino, Italy \\ b Department of Agrifood Production and Environmental Sciences, University of Florence, Piazzale delle Cascine, 18, 50144 Firenze, Italy \\ ${ }^{c}$ Kenyan Marine Fisheries Research Institute (KMFRI), P.O. Box 81651, Mombasa, Kenya \\ d Department of Earth Sciences, University of Florence, via La Pira, 2, Firenze, Italy \\ e Department of Physics, University of Florence, via Sansone 1, I-50019 Sesto Fiorentino, Italy
}

\section{A R T I C L E I N F O}

\section{Article history:}

Received 1 April 2014

Received in revised form 26 April 2014

Accepted 28 April 2014

\section{Keywords:}

Gastropod behaviour

Intertidal adaptation

Vertical migration

\begin{abstract}
A B S T R A C T
The mangrove gastropod Cerithidea decollata feeds on the ground at low tide and climbs trunks $2-3 \mathrm{~h}$ before the arrival of water, settling about $40 \mathrm{~cm}$ above the level that the incoming tide will reach at High Water (between 0 , at Neap Tide, and $80 \mathrm{~cm}$, at Spring Tide). Biological clocks can explain how snails can foresee the time of the incoming tide, but local environmental signals that are able to inform the snails how high the incoming tide will be are likely to exist. To identify the nature of these possible signals, snails were translocated to three sites within the Mida Creek (Kenya), 0.3-3 km away from the site of snail collection. The study sites had a much wider tidal range than the original site (up to $160 \mathrm{~cm}$ ), were dominated by Rhizophora mucronata trees and uninhabited by C. decollata. If cueing signals were linked to the upper mangrove belt (site-specific signals), the Avicennia marina area, translocation should affect snail behaviour; conversely, we could conclude that information on the height of the incoming tide should be widely available within the whole creek (widespread signals), independently from cues linked to the home area and home site. Tests were performed by releasing the snails close to vertical plastic pipes ( $2 \mathrm{~m}$ high) following a standardized procedure. Results revealed that snails, even in such unfamiliar surroundings, climbed higher and earlier on pipes where the tide level would be higher, thus allowing rejection of the hypothesis of site specific signals. Where the tide exceeded $80 \mathrm{~cm}$, however, snail effort was not sufficient to avoid submersion and snails had to climb higher. Hypotheses on widespread signals possibly involved in modulating the migratory behaviour of $C$. decollat $a$ are discussed.
\end{abstract}

(c) 2014 Elsevier B.V. All rights reserved.

\section{Introduction}

Intertidal animals experience continuous variation in habitat conditions due to daily tidal fluctuations which expose them alternately to marine and terrestrial biomes. For this reason, many species perform regular migrations to settle in the most suitable places for survival throughout the tidal phase (see Gibson, 2003 and references therein) and possess circatidal rhythms in synchrony with local tide conditions throughout the synodic month (the neap/spring cycle) (Morgan, 2001; Naylor, 2001). The adaptive value of the ability to know when the tide will arrive and how high it will be is unquestionable; however, an exhaustive explanation of the mechanisms guiding this ability has been formulated for only a limited number of species (see Naylor, 2001). Rhythmic tidal migrations, in fact, may be under the control of endogenous biological clocks, based on mechanisms of direct reaction

\footnotetext{
* Corresponding author. Tel.: + 39 3477777068; fax: + 39055222565.

E-mail address: vannini_m@unifi.it (M. Vannini).
}

to local environmental stimuli or controlled by both internal and external cues (Gibson, 2003; Naylor, 2001).

The gastropod Cerithidea decollata is an intertidal animal that performs regular daily migrations in synchrony with local tidal conditions to avoid submersion. This species, commonly found in Indo-Pacific mangroves, feeds on the ground at low tide and rests throughout the high tide on trees or any vertical substrata above the water level (Cockcroft and Forbes, 1981). Snails have been observed to climb trees 2-3 h before the arrival of water, settling approximately $40 \mathrm{~cm}$ above the level that the water will reach; subsequently, as the water retreats the majority of snails descend to the ground to feed (Vannini et al., 2008a).

While some aspects, such as the pattern of the migratory behaviour of $C$. decollata and similar species, have been extensively investigated (Cockcroft and Forbes, 1981; Harumi et al., 2002; Hodgson and Dickens, 2012; McGuinness, 1994; Vannini et al., 2006), studies are yet to clarify how the snails can foresee the level of the incoming tide (see Vannini et al., 2008c). Other intertidal molluscs, such as gastropods (Nerita textilis, Vannini and Chelazzi, 1978) and chitons (Acanthopleura 
spp., Chelazzi et al., 1983), living on exposed rocky shores are known to vertically migrate twice a day, preceding high tide, being regularly submerged or at least reached by the waves (at Spring Tide) or by water spray (at Neap Tide). In all of these cases animals retreat to a definite "home" (usually a hollow in the rock) irrespective of the level of the incoming tide.

In the Mida Creek (Kenya), the location of this study, C. decollata occupies the mangrove forest belt dominated by Avicennia marina, where the water level can vary from $0 \mathrm{~cm}$ to $80 \mathrm{~cm}$. The lower level A. marina areas are always partially submerged by the high tides, with the exception of a few days during Neap Tide, while the upper level areas are reached by water only during Spring Tide (Vannini et al., 2006). Since East African tidal patterns are complicated, due to both diurnal disparity and semi-monthly variation (from Neap Tide to Spring Tide), and as snails are not submerged by the tide, it is unlikely that snails may be guided by direct contact with water to predict the height of the incoming tide.

A biological clock is thought to control $C$. decollata migratory periodicity, as demonstrated by Vannini et al. (2008b), but the capability of this species to predict not only when the incoming tide will arrive but also how high it will be must presumably be based on internal and/or external factors that are yet to be thoroughly explained (Vannini et al., 2008c). Vannini et al. (2008c), by means of field experiments, demonstrated that $C$. decollata does not base such a skill on the perception of either marks left on the trunk by the previous high tides and/or by surrounding visual cues. We thus hypothesize that $C$. decollata may predict tide height relying on local environmental signals that are still unknown.

A possible step ahead could be an attempt to distinguish site-specific signals linked to the familiar site and environment (where learning processes may have occurred) from more widespread signals possibly available within the whole bay, even in sites unfamiliar to C. decollata.

Thus, in this study we aimed to investigate the migratory behaviour of $C$. decollata when translocated from a familiar site, the landward mangrove belt, to lower unfamiliar coastward sites dominated by Rhizophora mucronata. The inclination, sediment quality, vegetation structure and tidal amplitude of such different coastal sites provided a contrasting habitat in which the snails do not naturally occur. If snail behaviour appeared to be unaffected by the translocation, we could reject the hypothesis of the existence of cues restricted to the familiar sites. Otherwise, future investigations should further focus on specific local signals within these sites.

\section{Methods}

\subsection{Species and study sites}

C. decollata (L.) (Gastropoda, Caenogastropoda, Potamididae) is a widespread Indo-Pacific gastropod characterized by a shell approximately $15-25 \mathrm{~mm}$ long with a truncated apex. In East Africa it is commonly found within the A. marina belt (Cockcroft and Forbes, 1981; Macnae, 1963; Vannini et al., 2006), i.e. in the landward mangrove areas between the average height levels of High Water (HW) during Spring Tide and Neap Tide.

The study area was the Mida Creek ( $\left.03^{\circ} 21^{\prime} \mathrm{S} ; 39^{\circ} 59^{\prime} \mathrm{E}\right)$, a $3-4 \mathrm{~km}$ wide lagoon $80 \mathrm{~km}$ north of Mombasa (Kenya) and $25 \mathrm{~km}$ south of Malindi. Within the Mida Creek, the chosen study sites (Fig. 1) were as follows: 1) Bandarini, a mangrove forest dominated by an A. marina belt ( $150 \mathrm{~m}$ wide) on the upper levels and by a mixed $R$. mucronata and Ceriops tagal belt (100-200 m wide) on the mid-lower levels and 2) Dabaso and 3) Sita, both dominated by a thick (100-150 m wide) or thin (20-30 m wide) $R$. mucronata belt, respectively, with a few isolated $A$. marina trees on the upper levels. $C$. decollata does not inhabit the Dabaso and Sita sites, presumably due to the absence of a wide A. marina belt.

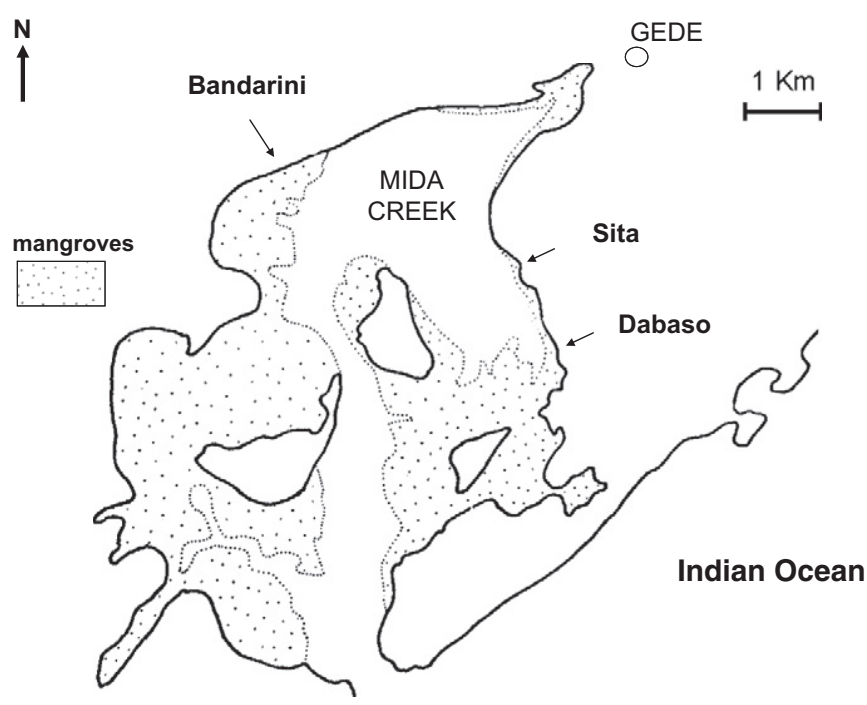

Fig. 1. Study site map. Mida Creek and the locations of the three experimental study sites.

\subsection{Animal observation and experimental procedures}

PVC pipes (length $2 \mathrm{~m}$, diameter $20 \mathrm{~cm}$ ), simulating Avicennia trees, were planted vertically in the muddy ground of the mangrove. Snails, collected at high tide and marked with white correcting fluid, were released at low tide at the base of the pipes following a tested procedure (Vannini et al., 2008c). The number of snails on each pipe varied between 40 and 70 individuals, corresponding to their average density on trees (Lori, 2008).

Snails climb tree trunks (and the pipes) following a relatively straight path until they settle. "Settling" involves the production of thick highly adhesive mucus and retreat of the foot and head into the shell. Thus, the entire body of the mollusc is hidden but remains in contact with the tree (or the pipe) due to the dried mucus filament. At the right moment snails extend their head and foot from their shell and start a downward migration. For unknown reasons, rarely do all snails exhibit this migration and a fraction (less than $5 \%$ ) may remain immobile on the trunk (or pipe), sometimes for more than one tide (see Vannini et al., 2008a).

Observations were performed by taking photographs (with simple digital cameras) of the pipes from four different positions, from the time of animal release until maximum HW. At night time flash was used. Precise measurement of snail position was possible due to horizontal marks drawn every $10 \mathrm{~cm}$ on the pipes, starting from ground level. PVC pipes have been shown to be efficient substitutes for tree trunks and they allow procedure standardization, facilitating the identification of exact position and image capture (Vannini et al., 2008c).

To calculate the exact time at which migration took place, we defined the time at which pipe semi-saturation occurred as $F_{50}$, i.e. the time at which half of the total number of snails that finally settled on the pipe was positioned on the pipe (Vannini et al., 2008b).

Two different translocation experiments from familiar to unfamiliar conditions were performed; the first experiment was repeated three times, on three different days at three different sites (Bandarini, Sita and Dabaso: three-site experiment) and the second experiment was performed once at a single site (Sita: single-site experiment) during January-February 2013. After the experiments, all translocated snails were returned to their original locations.

\subsubsection{Three-site experiment}

Two pipes were placed vertically in the mangrove sediment in two locations in Dabaso and Sita and in three locations in Bandarini (Fig. 1). The relative level of the various pairs of pipes within each site is listed in Table 1. Bandarini landward and Bandarini middle 
Table 1

Relative depth $(\mathrm{cm})$ of various pairs of pipes within the three experimental sites, assuming the landward mangrove fringe in Bandarini as $0 \mathrm{~cm}$. Bandarini landward and Bandarini middle correspond to the only sites inhabited by C. decollata.

\begin{tabular}{lc}
\hline Sites & Depth \\
\hline Bandarini landward & 0 \\
Bandarini middle & 55 \\
Bandarini seaward & 106 \\
Sita landward & 105 \\
Sita seaward & 148 \\
Dabaso landward & 106 \\
Dabaso seaward & 160 \\
\hline
\end{tabular}

correspond to the only locations inhabited by $C$. decollata, while all the other pipes were placed in unfamiliar locations.

All animals tested for experiments were from Bandarini middle, the control location. Bandarini landward is the only experimental location where translocated snails experienced familiar tidal conditions, with a lower HW level compared to Bandarini middle. In the remaining locations, snails were exposed to tide levels higher than those of their home environment (Table 1).
Animals were collected one evening at approximately 20:00 h and transported to Gede (about $3 \mathrm{~km}$ away, Fig. 1). From Gede, animals were transported in one vehicle to Sita and Dabaso while another vehicle transported animals back to Bandarini. Animals were released simultaneously at all locations at the time of Low Water (LW) close to the pipes. The time from capture to release did not exceed $30 \mathrm{~min}$. Photographs were taken every hour between LW and maximum HW. Experiments were conducted on January 26 and 28 and February 8 2013. During the first two sampling sessions the landward pipes at Sita and Dabaso were not used.

\subsubsection{Single-site experiment}

A single series of eleven pipes, placed $5 \mathrm{~m}$ apart, were set in Sita along the land-sea axis on January 31 2013. Animals were captured in Bandarini middle and released during the diurnal low tide in Sita following the procedure described above. Photographs of pipes were taken every hour until the time of HW.

Three-site experiments were performed at night time to reduce micro-climatic differences due to different vegetation densities and canopy structures of the five experimental locations.

Pearson correlation tests (with Bonferroni correction) were applied to correlate 1) water level at HW and snail cluster height on the trunk

26 Jan.
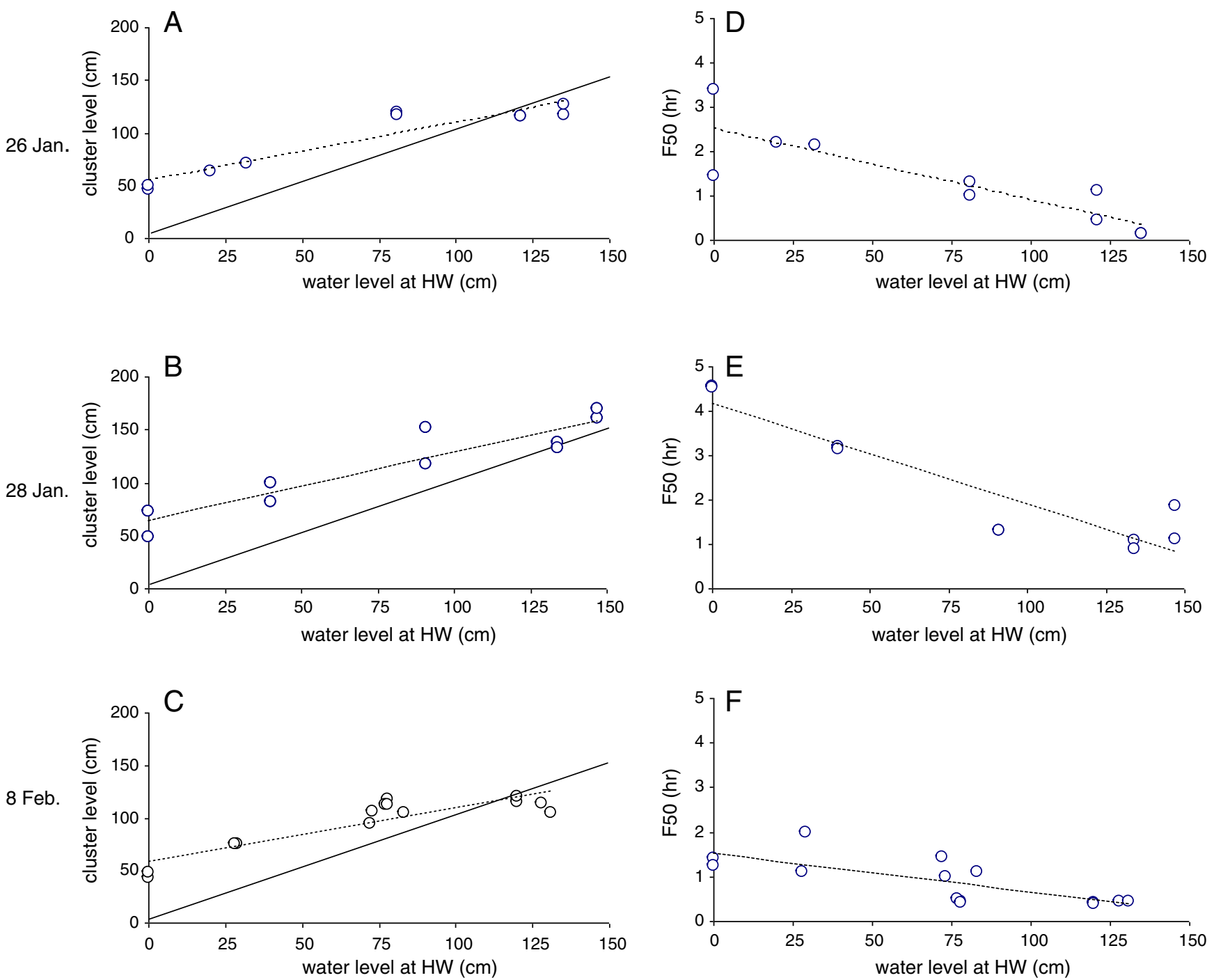

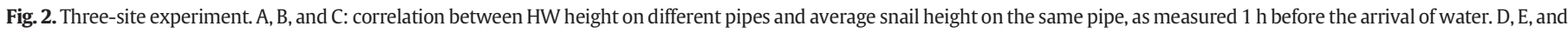

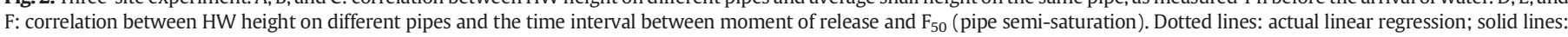
linear regression lines with $\mathrm{b}$ coefficient $=1$. 


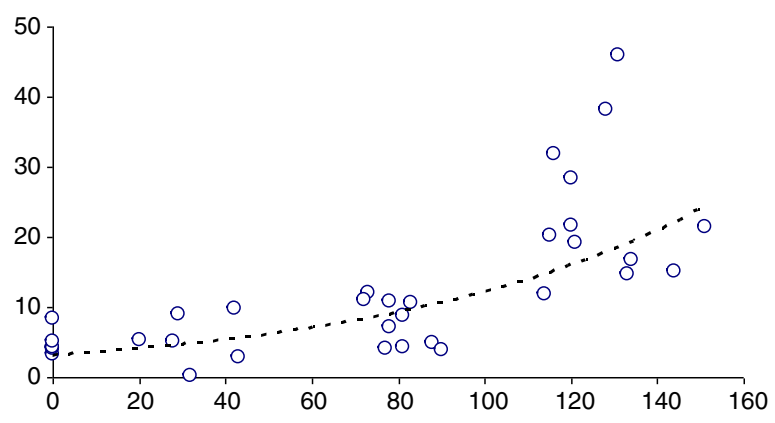

Fig. 3. Three-site experiment. Correlation between HW height on different pipes and the extra distance $(\Delta)$ snails have to climb after water arrival (about $2 \mathrm{~h} 30 \mathrm{~min}$ after release). Dotted line, exponential regression line.

before the arrival of high tide and 2 ) water level at $\mathrm{HW}$ and $\mathrm{F}_{50}$ values. $\mathrm{t}$-Tests were also applied to test whether regression coefficients $b$ obtained from correlation tests were significantly different from 1 .

Each point represented in Figs. 2-5 indicates the average level of 50-70 snails, which actively tend to cluster. About $95 \%$ of them usually settle within a $35 \mathrm{~cm}$ interval around the average. Easy-Stat software was used.

\section{Results}

\subsection{Three-site experiment}

In all cases, snails climbed the pipes after release settling higher in locations where the tide was going to be higher (Fig. 2A-C). In addition, snails appeared to climb pipes much earlier than the water arrival and spent less time on the ground after release in these locations (Fig. 2D-F). Snail height was thus positively correlated (Fig. 2A-C) and $\mathrm{F}_{50}$ negatively correlated with water level at HW (Fig. 2D-F). Table 2 displays the results of correlation tests applied to the six diagrams shown in Fig. 2.

Fig. 2(A-C) displays the correspondence between water level and snail cluster level (solid lines), which was significantly different from the actual regression lines (Table 2). In cases of the highest water levels, the snails did not settle high enough to avoid submersion and were forced by the water to climb higher or, occasionally, remain submerged.

A high correlation $(\mathrm{r}=0.734$; $\mathrm{df}=32 ; \mathrm{P}<0.001)$ between the HW level and the extra-distance the snails had to climb after the water arrival can be seen by cumulating all the data of Fig. 2A-C (Fig. 3). It is evident that snail cluster level is approximately the same both before water arrival and during HW on landward pipes while on more seaward pipes snails tended to cluster too low and about $10 \%$ of them had to climb higher when the water arrived, even an extra $45 \mathrm{~cm}$ (Fig. 3).

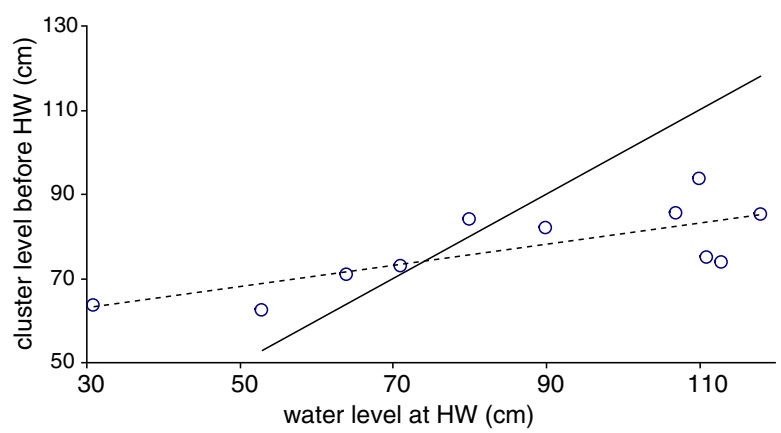

Fig. 4. Single-site experiment. Correlation between HW height on the 11 pipes and average snail height on the same pipe, 140 min before actual water arrival. Dotted line, actual exponential regression line; solid line, liner regression lines with $\mathrm{b}$ coefficient $=1$.

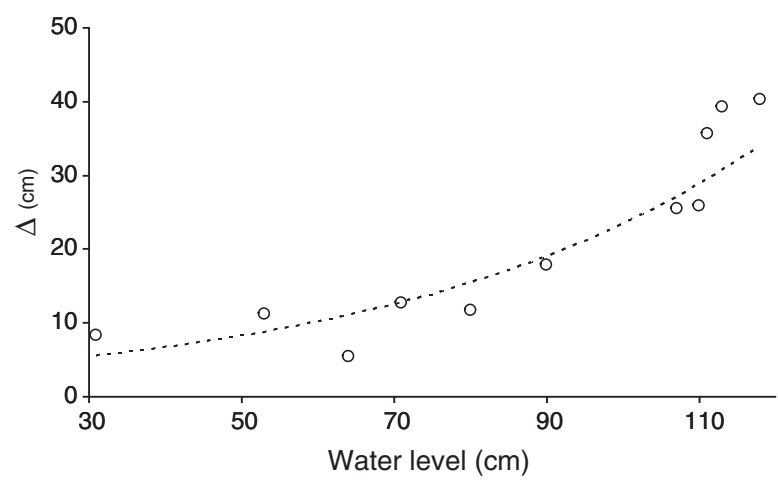

Fig. 5. Single-site experiment. Correlation between HW height on different pipes and the extra distance $(\Delta)$ snails had to climb after water arrival (about $2 \mathrm{~h}$ later). Dotted line, exponential regression line.

\subsection{Single-site experiment}

Fig. 4 shows the level at which snails settled $1 \mathrm{~h}$ before the water reached the base of the lowest pipe (about $140 \mathrm{~min}$ before actual HW). Snails clustered on pipes more than $2 \mathrm{~h}$ in advance of $\mathrm{HW}$ at a height proportional to the incoming HW level (Fig. 4; $r=0.748$; $\mathrm{df}=9 ; \mathrm{P}<0.001)$. In this experiment it was also evident that snails tended to climb higher on pipes where the water level would be higher; but, again, they did not avoid submersion in cases when HW levels were higher than about $80 \mathrm{~cm}$. Thus, the water arrival induced about $40 \%$ of the snails to climb an extra distance; this was only a few centimetres on the pipes with a HW level of $30 \mathrm{~cm}$, but as much as approximately $40 \mathrm{~cm}$ on pipes with a HW level higher than $110 \mathrm{~cm}$. This extra distance was highly correlated with HW level (Fig. 5; $r=0.889$; $\mathrm{df}=9 ; \mathrm{P}<0.001)$.

\section{Discussion}

C. decollata, within the Mida Creek mangrove, appeared to be able to access, and behave according to, information concerning the tide level at HW in all cases of experimental translocation. Snails climbed to greater heights on pipes that faced higher water levels, while the time spent on the ground before climbing was proportionally reduced. This snail behaviour was observed in cases where snails were tested in unfamiliar locations (Bandarini lower, Sita and Dabaso landward and seaward) surrounded by unfamiliar R. mucronata, and in their natural habitat (Bandarini lower and middle) surrounded by familiar A. marina. Tide level in unfamiliar locations was up to twice as high (up to $160 \mathrm{~cm}$, Dabaso) as the tide snails usually experience in their natural habitat (Bandarini landward $0-10 \mathrm{~cm}$ or Bandarini middle $0-80 \mathrm{~cm}$ ). The height snails climbed was proportional to the water level, but when HW exceeded $80-100 \mathrm{~cm}$ (varying according to location) they were not able to calculate exactly how high they should climb to avoid being reached by the water and were, in some cases, submerged.

Table 2

Correlation significance of data presented in Fig. 2. $\mathrm{r}=$ correlation coefficient; $\mathrm{df}=$ degree of freedom; $\mathrm{P}=$ corresponding level of significance of $\mathrm{r}$; $\mathrm{a}=$ intercept; $\mathrm{b}=$ regression coefficient; $\mathrm{t}_{\mathrm{b} \diamond 1}=\mathrm{t}$ test applied to compare whether the hypothesis that measured $\mathrm{b}$ may be different from 1 or not; $\mathrm{P}=$ level of significance at which the above hypothesis can be rejected.

\begin{tabular}{llrlllll}
\hline Diagram & $\mathrm{r}$ & $\mathrm{df}$ & $\mathrm{P}<$ & $\mathrm{a}$ & $\mathrm{b}$ & $\mathrm{t}_{\mathrm{b} \odot 1}$ & $\mathrm{P}<$ \\
\hline A & 0.944 & 8 & 0.001 & 54.25 & 0.553 & 6.541 & 0.001 \\
B & 0.932 & 8 & 0.01 & 59.49 & 0.655 & 3.986 & 0.005 \\
C & 0.889 & 12 & 0.001 & 58.31 & 0.515 & 6.347 & 0.001 \\
D & 0.866 & 8 & 0.001 & & & & \\
E & 0.924 & 8 & 0.001 & & & & \\
F & 0.745 & 12 & 0.01 & & & & \\
\hline
\end{tabular}


Direct observations indicated that when still active (foot visible out of the shell) snails can climb higher but if they already had sealed themselves within the shell before water arrival, they will not climb further.

The behaviour of the snails suggests that they are able to acquire information about the future HW level from widespread signals available within the mangrove bay, and thus the hypothesis that snails may rely on direct cues restricted to the familiar sites (site-specific signals) can be rejected. On the other hand, when snails are far from their home site, widespread signals seem to be incomplete or insufficient.

Direct information, such as direct view or smell of the sea, cannot be involved in prediction hours in advance and does not carry the detailed information required. In fact, olfactory cues can likely only inform snails that they are in the vicinity of the sea. In addition, if we consider that in the Bandarini landward and middle locations the sea edge is hundreds of metres away, beyond a $150 \mathrm{~m}$ wide $R$. mucronata forest, when upward migration commences (Vannini et al., 2006), we can definitively eliminate obvious direct stimuli as cues for migration.

The behaviour of snails translocated from the middle to the landward Bandarini site, i.e. within familiar conditions, does not fully accord with previous observations (Vannini et al., 2008b), probably due to the different translocation procedures in the two studies. Nevertheless, prediction of water level appears to be more accurate in familiar locations that are subject to tidal excursions within an expected range: it is probable that some type of information is memorized by snails (Lazzeri et al., in press) and that this information plays a role in water level prediction.

We are currently exploring several hypotheses to explain the origin of possible widespread cueing signals. In response to variation in groundwater salinity due to tidal water motion, mangrove roots could generate electrical signals (Fromm and Fei, 1998), which could be perceived by snails when creeping on the ground. In addition, plants could react to changes in groundwater salinity by releasing volatile organic compounds (Dicke et al., 2003; Loreto and Schnitzler, 2010; Shulaev et al., 1997). A further hypothesis may rely on the effect of the oceanic wave reaching the coast and the barrier reef (Ferretti et al., 2013; Marzorati and Bindi, 2008), or alternatively the water pressure on the coastal limestone could induce changes in ground resistivity (Versteeg and Johnson, 2008; Wilson et al., 2006). Nothing is known about the snails' capability to react to these types of signal. Finally, it is obvious that a biological tidal clock informing the snails when the tide will occur would not supply any reliable information on tide height, especially in sites where tides are much higher than those that snails usually experience.

In conclusion, we believe that site specific and widespread signals are almost certainly both involved, together with internal information, in modulating the migratory pattern of $C$. decollata. Such behavioural plasticity is a fundamental mechanism to avoid being submerged by High Water.

\section{Acknowledgements}

Many thanks are due to Dr. Renison Ruwa (KMFRI, Mombasa) and Dr. Mohamed Omar Said (KWS, Mombasa) for their support and encouragement. This work could not have been carried out without the help of the Mida Creek guides Mohamed Ali Bakari, Said Athman Said, and Dickson Thoya Said and the Florence University students Sara Boschi, Federico del Sala, Lucrezia Giovannini, Martina Scapecchi, Gianluca Stasolla and Margherita Vanni. Funds were obtained from the Department of Biology of the University of Florence. We also thank Jenny Booth for the linguistic revision of the manuscript. [SS]

\section{References}

Chelazzi, G., Focardi, S., Deneuborg, J.L., 1983. A comparative study on the movement patterns of two sympatric tropical chitons (Mollusca: Polyplacophora). Mar. Biol. 74, $115-125$.

Cockcroft, V.G., Forbes, A.T., 1981. Tidal activity rhythms in the mangrove snail Cerithided decollata (Linn.) (Gastropoda: Prosobranchia: Cerithiidae). S. Afr. J. Zool. 16, 5-9.

Dicke, M., Agrawal, A.A., Bruin, J., 2003. Plants talk, but are they deaf? Trends Plant Sci. 8, 403-405.

Ferretti, G., Zunino, A., Scafidi, D., Barani, S., Spallarossa, D., 2013. On microseisms recorded near the Ligurian coast (Italy) and their relationship with sea wave height. Geophys. J. Int. 194, 524-533.

Fromm, J., Fei, H.M., 1998. Electrical signaling and gas exchange in maize plants of drying soil. Plant Sci. 132, 203-213.

Gibson, R.N., 2003. Go with the flow: tidal migration in marine animals. Hydrobiologia $503,153-161$.

Harumi, O., Eiko, M., Kiyonori, T., 2002. Tree climbing behavior of the snail Cerithidea rhizophorarum (Gastropoda: Potamididae). Venus 61, 215-232.

Hodgson, A.N., Dickens, J., 2012. Activity of the mangrove snail Cerithidea decollata (Gastropoda: Potamididae) in a warm temperate South African estuary. Estuar. Coast. Shelf Sci. 109, 98-196.

Lazzeri, A.M., Mwangi, G., Tasselli, P.L., Vannini, M., Fratini, S., 2014. Cerithidea decollata (Mollusca, Potamididae) vertical migration: do snails learn from conspecifics? Ecol. Ethol. Evol. 26 (in press)

Loreto, F., Schnitzler, J.P., 2010. Abiotic stresses and induced BVOCs. Trends Plant Sci. 15, $154-166$.

Lori, E., 2008. Zonation and Adaptation of Gastropod to Extreme Environment: The Case of Cerithidea decollata and of Melanopsis etrusca. University of Florence (Ph.D. Thesis).

Macnae, W., 1963. Mangrove swamps in South Africa. J. Ecol. 51, 1-25.

Marzorati, S., Bindi, D., 2008. Characteristics of ambient noise cross correlations in Northern Italy within the frequency range of 0.1-0.6 Hz. Bull. Seismol. Soc. Am. 98, 1389-1398.

McGuinness, K.A., 1994. The climbing behaviour of Cerithidea anticipata (Mollusca: Gastropoda): the role of physical versus biological factors. Aust. J. Ecol. 19, 283-289.

Morgan, E., 2001. The moon and life on Earth. Earth Moon Planet. 85-86, 279-290.

Naylor, E., 2001. Marine animal behaviour in relation to lunar phase. Earth Moon Planet. 85-86, 291-302.

Shulaev, V., Silverman, P., Raskin, I., 1997. Airborne signalling by methyl salicylate in plant pathogen resistance. Nature 385, 718-721.

Vannini, M., Chelazzi, G., 1978. Field observations on the rhythmic behaviour of Nerita textilis (Gastropoda: Prosobranchia). Mar. Biol. 45, 113-121.

Vannini, M., Rorandelli, R., Lähteenoja, O., Mrabu, E., Fratini, S., 2006. Tree-climbing behaviour of Cerithidea decollata (L.), a Western Indian Ocean mangrove gastropod (Mollusca, Potamididae). J. Mar. Biol. Assoc. UK 86, 1429-1436.

Vannini, M., Coffa, C., Lori, E., Fratini, S., 2008a. Vertical migrations of the mangrove snail Cerithidea decollata (L.) (Potamididae) through a synodic month. Estuar. Coast. Shelf Sci. 78, 644-648.

Vannini, M., Mrabu, E., Cannicci, S., Rorandelli, R., Fratini, S., 2008b. Rhythmic vertical migration of the gastropod Cerithidea decollata in a Kenyan mangrove forest. Mar. Biol. 153, 1047-1053.

Vannini, M., Lori, E., Coffa, C., Fratini, S., 2008c. Cerithidea decollata, a snail that can foresee the future? Anim. Behav. 76, 983-992.

Versteeg, R., Johnson, T., 2008. Using time-lapse electrical geophysics to monitor subsurface process. Lead. Edge 27, 1488-1497.

Wilson, S.R., Ingham, M., Conchie, J.A., 2006. The applicability of earth resistivity methods for saline interface definition. J. Hydrol. 316, 301-312. 